\title{
Will Canada bend its health spending curve?
}

A fter a decade of growth by leaps and bounds, health spending in Canada is starting to slow down.

Canada is projected to spend an all-time high of $\$ 211.2$ billion on health care this year, the Canadian Institute for Health Information (CIHI) reveals in a new report. But for the first time in 15 years, the rate of growth in health spending has not kept pace with inflation and population growth.

CIHI projects health expenditures will increase by $2.6 \%$ this year - less than half the average growth of $7 \%$ per year between 2000 and 2010. After accounting for inflation and population changes, health spending will actually drop $0.2 \%$.

"It's the lowest rate of growth we've seen since the mid-90s," says Chris Kuchciak, CIHI's manager of health expenditures.

He suggests the trend may indicate the start of a "bending of the spending curve," as growth in total health outlays has slowed each year since 2011. "Given the weaker economy and budget deficits, governments are really paying attention in terms of containing spending."

That new restraint is most evident in "significantly lower" increases in drug expenditures, says Kuchciak. CIHI reports drug spending will grow to $\$ 34.5$ billion in 2013, up 2.4\% from 2012. In comparison, "ten years ago, we were seeing double digit growth rates in annual drug spending."

Kuchciak attributes the change to government efforts to purchase drugs in bulk and control generic prices. Increasing substitution of generic

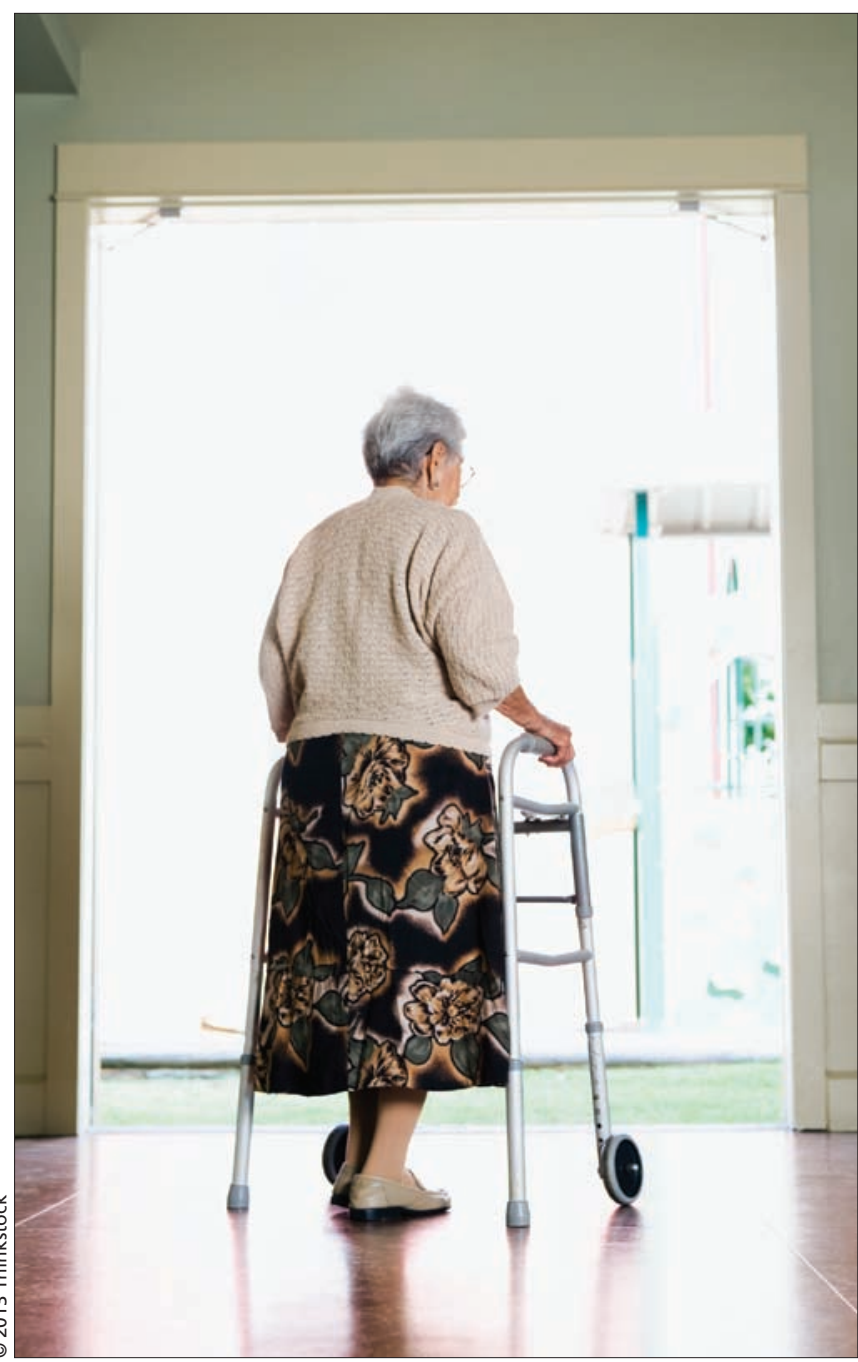

Contrary to popular projections, Canada's aging population contributes less than $1 \%$ to growth in annual health spending.

physician compensation remains the fastest-growing category of health spending. CIHI expects spending on doctors to reach $\$ 31.4$ billion in 2013, a $3.6 \%$ increase over the previous year, due in part to hikes in physician fees.

Meanwhile, population aging has been a relatively modest contributor to health costs in recent years, contrary to popular projections.

"On a year-to-year basis, it actually contributes less than $1 \%$ to the growth in health spending," says Kuchciak. "It's more like a glacier than a tsunami, so health systems do have time to adapt to the changing needs of the population."

The greatest challenges in that regard are likely still to come, as more seniors pass their 80th birthdays. CIHI reports that per person spending for seniors aged 80 and older (\$20 387) is more than three times that for seniors aged 65-69 (\$6431), and more than eight times that for Canadians aged 1-64 (\$2341).

It's unclear if Canada's new-found restraint in total health spending will endure, says Kuchciak. "After three or four years of restraint in the mid-1990s, we saw a huge reinvestment in health care into the last decade, which some people would

medicines for brand-name treatments and a decline in the number of new drugs brought to market have also dampened drug spending.

Growth in hospital and physician spending has also slowed. However, say was to make up for the cuts. The issue to monitor in the future is whether the changes we're seeing will be sustained." - Lauren Vogel, CMAJ

CMAJ 2013. DOI:10.1503/cmaj.109-4649 